\title{
An Empirical Study on the English Classroom Interaction Model from the Perspective of Dynamic Systems Theory
}

\author{
Yan Qiao \\ Luoyang Institute of Science and Technology, Luoyang, China
}

\begin{abstract}
Dynamic Systems Theory (DST) has provided a new perspective for SLA studies but it is rarely applied in empirical researches of classroom interactions. Under the framework of DST, this paper explores the current situation and analyzes the problems of classroom interaction of non-English majors' college English through questionnaire, interview and class observation. Based on the findings, this paper proposes some teaching strategies to create a dynamically harmonious class and enrich the empirical studies of DST.
\end{abstract}

Keywords:DST; College English; Classroom Interaction; Problems; Teaching Strategies

\section{I.Introduction}

College English, as an indispensable part of the curriculum system, plays an active role in promoting the cultivation of high-quality talents in the technology-oriented universities. Classroom interaction plays an important role in second language teaching since classroom interaction influences the classroom atmosphere, the feedback in class, students' participation, and the effectiveness of classroom teaching. At present, there are still some problems in college English classroom teaching and interaction, such as insufficient cultivation of students' self-learning ability, and students' anxiety in classroom interaction. Therefore, how to carry out correct and effective forms of interaction in class is particularly important to improve students' ability to communicate in English. Dynamic SystemsTheory(shortened as DST) provides a new perspective for the study of second language classroom interaction. Dynamic systems theory is a relatively novel research paradigm in second language acquisitions and more researchers have shown increasing interest in challenging this field[1].Therefore, this study intends to explore the classroom interaction of the course "College English" in the case of a technology-oriented university from the perspective of dynamic systems theory by using questionnaire, interview and classroom observation to present the current situation of the classroom interaction, analyze the potential problems and put forward teaching strategies.

\section{II.A Brief Introduction to Dynamic Systems Theory}

Dynamic systems theory focuses on how to study language development from a dynamic and systematic approach. Dynamic Systems Theory, originated in Newtonian mechanics, was defined as "an evolution rule that defines a trajectory as a function of a single parameter (time) on a set of states (the phase space) is a dynamical system"[2] Larsen-Freeman[3] was the first person to apply DST to second language acquisition (SLA) investigations. She pointed out the great potential of the theory in applied linguistics and the field of second language acquisition, and proposed that language development has possessed all the features of the complex, dynamic and nonlinear system. At the macro level, DST has something in common with the ecological view of language and the sociocultural theory, both of which emphasize the complicated interactions within and between the sociocultural system and the individual cognitive system. At the micro level, this view coincides with the usage-based view of language, which holds that language development does not follow a straight line and that each state depends on the previous one.de Botet al. [4]proposed that the theory of dynamic systems should be regarded as the general theory of second language development that can fully explain the key issues in the process of second language acquisition, such as the multi-level interaction between cognition and environment, the nonlinear characteristics of dynamic language development, the influence of mother tongue and individual differences. However, it needs to be admitted that the theory of dynamic systems is a very complex theoretical framework, and somekeyfeatures of dynamic systems will

ISSN: 0010-8189

(C) CONVERTER 2021 
be applied in this study:complete interconnectedness, the differentiation and initial conditions, and attractor states.

So far, in addition to Larsen-Freeman, van Geert, five Graces group, de Bot et al., and Dörnyei, who are mainly from the United Kingdom, the United States, the Netherlands and some other countries, are among the most influential foreign scholars in the study of second language acquisition based on DST. Their studies mainly focused on language, language use, mother tongue/second language acquisition, SLA research methods etc., but few researches were conducted specifically on second language acquisition in the classroom context[5]. The theory was introduced into China even late, and the number of related papers in the core journals of foreign languages is also very limited. On the whole, the relevant researches in China are still in the initial stage, most of which are introduction to the theory but few original and empirical researches.

Therefore, taking non-English major students in Luoyang Institute of Science and Technology as research objects, this empirical study investigated the current situation such as students' participation and feedback, and potential problems in College English classroom interaction through a combination of quantitative and qualitative methods like classroom observation, questionnaire and interviews based on the dynamic systems theory, and proposed some teaching strategies.

\section{III.Current Situation and Problems in Classroom Interaction Based on DST}

The teaching of College English (2) in 4 classes were closely observed during the investigation. Besides, the questionnaire named "A Survey on Interaction between Teachers and Students in College English Class" was distributed to 10 classes of freshman and sophomore through an online questionnaire platform. The students came from five majors, including Environment and Chemistry, Materials, Machinery, Business Administration and Automation. A total of 177 surveys were collected. The questionnaire includes 35 multiple-choice questions which aimed to understand the students' psychological state and their feedback in classroom interaction. Four students from the class observed were selected for the interview. The interview contained eight open questions, aiming to further understand and analyze the feelings, opinions and feedbacks of students after participating in the class interaction. Based on the data collected from questionnaire, classroom observation and interview, the main problems of classroom interaction were analyzed from the perspective of the dynamic systems theory.

In the first place, there was an imbalance in the classroom teaching system. According to DST, all components within one system can themselves being considered as dynamic subsystems and these (sub)systems were often interlinked on all possible levels[6]. The classroom teaching has created a system of its own andone of its subsystems is the interaction between students and the teacher. Many variables such as students, teacher, textbook, etc. at different levels and sub-levels are inter-connected and keep on interacting to create a dynamic learning environment with potential meaning so that students could be motivated to communicate in English due to the adaption and self-organization among these variables.Since the teaching reform of College English, the great changes in the classroom environment are reflected in the application of a large number of information technology, the reconstruction of teaching concepts and the change of classroom teaching subjects. However, some teachers have not changed their teaching concepts in time to improve their teaching skills. Teachers spent the majority of time in giving lectures instead of organizing activities for students to practice. According to the classroom observation and questionnaire, $40 \%$ of the students thought that they barely had chance to practice and interact since the teacher talked too much. What's more, $56 \%$ of the students held that IRF (initiation response feedback), i.e., teacher poses questions and students answer, was the only model of classroom interaction which was boring and ineffective. Most of the students were inactive and few students take the initiative to answer questions. 50\% of the students said they would not take the initiative to answer questions or ask questions in the classroom, because "I'm not willing to speak English", "my oral English is really bad", "it is difficult to express my views accurately in English", students said in the interview. In the interviews, they expressed their ideas about English class which was boring and they gained little.It can be seen that teachers' behavior and teaching design will definitely influence students' performance because as a system the students is constantly changing and adapting themselves to 
"coordinate" with the teachers. When the teacher failed to encourage the classroom interaction and motivate students' learning desires, students would lose interest and passion so that the whole system of classroom teaching would malfunction.

Secondly, the ignorance of initial conditions and differentiation in the system lead to the mismatch in teaching and learning goals between teacher and students. Another important characteristic of a dynamic system is its initial conditions which is defined by Verspoor[7] as "the conditions subsystems are in when the researcher starts measuring". Different dynamic systems may differ with one another in their initial conditions [8]. If we considerstudent's language development as a system, each one may have different initial conditions which will develop and follow one's own track. Even if their initial conditions were similar, they may end up in a different way because each system develops in a different speed, intensity or timing. We have found two major disagreements between teachers and students through classroom observation, questionnaire and interviews. First, based on the teaching curriculum of College English, teachers focused on the cultivation of students' communicative abilities to use English in their daily life and future work. While students who grew up in an exam-oriented education still took passing CET 4 and CET 6 (College English Test) as their target of English learning. Classroom observation showed that some students were doing sample test papers during the teaching. Second, $70 \%$ of students preferred student-centered classroom teaching and thought classroom interaction helps improve their English level. 64\% expressed their willing ness to participate in group activities, however, not all students would actively participate in the real class. "Two students in our group never got involved because they thought their English is too bad," a student said in the interview. "It's always those two or three who were active to speak and others were keeping silent all the time". Therefore, although students have a positive attitude towards classroom interaction, due to the different initial conditions of language development or affective factors in learning process, there are contradictions between teachers and students about the goals of learning tasks. Some students couldn't not cooperate with teachers to complete classroom interaction, and some students were even not willing to participate in the classroom interaction. The teacher's failurein recognizingstudents' individual differences andinitial conditions and adjusting the teaching accordingly would lead to the ineffectiveness of classroom teaching.

Thirdly, the misuse of attractor states leads to the disconnection between the teaching and spatialenvironment.An attractor state refers to "a critical value, pattern, solution or outcome towards which a system settles down or approaches over time" [9]. The spatial environment of the classroom could be a control parameter referred as an attractor state or a combination of attractor states which could be a driving force of the system[10]. Through classroom observation, it's found that the layout of desks and chairs in the classrooms were fixed and arranged in a matrix style, with teachers' platform placed in the middle of the front of the classroom, which reflects the teacher-centered model and is not conducive to carry out interactive learning like group discussion and other classroom activities. In addition, the classes are overcrowded with over 60 students, therefore, it's difficult to ensure that most students could have time and opportunity to practice their language skills and express their ideas. The spatial environment failed to be the attractor state to improve the classroom interaction and teaching effect. On the contrary, the excessive class size and fixed seats aggravated the deterioration of learning environment and caused teaching inefficiency. The teaching environment lags behind the new teaching ideas and methods, which also led to the imbalance of the system.

\section{IV.Teaching Strategies for Classroom Interaction}

Under the framework of dynamic systems theory, college English class should be a dynamic, interconnected and complete teaching system. The teaching scene, the knowledge system and the teacher-student relationship formed in the teaching process constitute a multi-dimensional college English classroom teaching model, which is integrated with between the entirety and level, order and disorder, and fine-tuning and self-organization. The effective classroom interaction directly determines the learning effect in the class. In order to solve the problems in current classroom interaction analyzed in previous part, some teaching strategies were proposed as follows:

ISSN: 0010-8189

(C) CONVERTER 2021 
First of all, we should construct a balanced interactive mechanism between teachers and students, converting the static linear relationship to the dynamic nonlinear relationship. Teachers should not only control the discussion of the topic, but also trigger students' critical thinking through open questions, and provide students with certain opportunities to generate subtopics. Teachers should respond to students' views in time, and give feedback to students' language errors and help them to correct. At the same time, teachers should ensure that the interaction is open to other students and help them get correct understanding and language input. The interaction between teachers and students is the foundation of the dynamic system which is generated by both teachers and students and the teaching environment. Teachers and students should change their traditional identities. Teachers should change from traditional knowledge producers to course organizers and trainers. Students should also change their roles from passive receivers to knowledge builders and teachers' collaborators. Teachers and students can constantly generate new understanding of knowledge and experience through interaction and dialogue, to grow together and improve each other in order to form a complete nonlinear teaching and learning system.

Second, teachers should carry out inquiry-based classroom interaction to build an interactive and cooperative teaching mode, avoiding the use of IRF as the only interactive model. Inquiry-based classroom interaction is a non-linear interactive activity between teacher and students, which encourages students to construct their own knowledge system and cultivate their inquiry ability and innovation ability [11]. In College English classroom teaching, the inquiry-based classroom interaction could be achieved in the following ways: under the guidance of teachers, students independently put forward questions and tasks according to their own interests and abilities. Through personal exploration and cooperation between teachers and students, after students carry out task-based research and learning, they make presentations or role-play in class to present their own research to peers and teachers. Finally, they may write a research paper to realize the purpose of putting what they've learned into practice in inquiry-based teaching. In addition, teachers can also design project-based and task-based group activities to promote students' active learning and establish a harmonious relationship between teachers and students.

Last but not the least, Third, the teaching environment should be improved and the number of students in a class should be reduced. The traditional classroom with fixed desks and chairs is more suitable for the teacher-centered teaching model, which cannot meet the demand of a collaborative, interactive and dynamic teaching system. Therefore, the desks and chairs should be easy to move so that teachers can adjust according to the needs of teaching activities. For example, during a group discussion, the tables and chairs should be placed in a circle for 4-6 students, which is convenient for teachers and students to communicate with each other. It would be easier for teachers to assist students to fulfill the task and answer questions at any time. In such spatial environment students would focus more on active learning and exploration of knowledge. Creative thinking would be cultivated and opportunities would be offered for students to practice. Collaborative classroom environment could better reflect the self-organization in the classroom teaching system, emphasize the respect for individuals, and highlight the cultivation of students' collaborative ability.

\section{V.Conclusion}

The application of DST is not fully developed in SLA in China and most scholars focus on the theoretical analysis since it is a highly complex theory and hard to understand. There are even fewer empirical studies on SLA classroom teaching. The author has made an effort to apply DST to the classroom interaction of the second language class in an empirical research. This paper has investigated the current situation of classroom interaction of College English course through observation, questionnaire and interview, analyzed the potential problems and proposed some teaching strategies at the end. The author hopes this paper could attraction more attention to the application of DST to SLA studies and cast some light on the understanding of classroom interaction from a new perspective. In addition, since classroom interaction is a key element in the teaching of second language, it hopes that this paper could help teachers improve their teaching design of classroom activities through a new angle and better cultivate students' practical skill of language use and comprehensive abilities.

ISSN: 0010-8189

(C) CONVERTER 2021 


\section{References}

[1] Luanyi, Xiao, “A Multiple-Case Study of Self-perceived Affective Experiences and Self-reported Foreign Language Performances from a Dynamic Systems Theory Perspective,"Shanghai: ShangHai Jiao Tong University Press, 2018.

[2] Meiss, J.,"Differential Dynamical Systems," Philadelphia: Society for Industrial and Applied Mathematics, 2007.

[3] Larsen-Freeman, D., “Chaos/Complexity science and second language acquisition,”Applied Linguistics 18,Pp. 141-165, 1997.

[4] De Bot, K., W. Lowie\& M. Verspoor,“A dynamics systems theory approach to second language acquisition” Bilingualism Language and Cognition 10, pp. 7-21, 2007.

[5] Jinfen, Xu\& Pengfei, Lei, “The Studies of SLA Based on Dynamic Systems Theory: Framework and Methods,'Foreign Language Teaching and Resear.1, pp. 22-29, 2017.

[6] Geert P.,Van, "Dynamic Systems Approaches and Modelling of Developmental Processes"London: Sage, 2003.

[7] Verspoor, M. Initial Conditions. UK: Multilingual Matters, 2014.

[8] Verspoor, M. Initial Conditions. UK: Multilingual Matters, 2014.

[9] Hiver, P. “Once Burned, Twice Shy: the Dynamic Development of System Immunity in Teachers," UK: Multilingual Matters, 2014.

[10] Yongyan, Zhen, “The Application of Dynamic Systems Theory to SLA Studies--- A Case Study of SLA Vocabulary Development,"Modern Foreign Languages 3, pp 303-309, 2011.

[11] Yinghao, Jin, "A Study of College English Classroom Teaching under the Framework of Dynamic Systems Theory,” Daqing: Northeast Petroleum University, 2016. 